\title{
AVALIAÇÃO DA PARTICIPAÇÃO DE PROFESSORES NA CONSTRUÇÃO DO CURRÍCULO DE CIÊNCIAS: FATORES INTERVENIENTES NO CONDICIONAMENTO DOS AVANÇOS
}

GARCIA, Paulo Sérgio *

\begin{abstract}
RESUMO
A tradição brasileira sinaliza que a construção do currículo, na imensa maioria das vezes, recorreu à atuação de consultores e especialistas em educação perfazendo um trabalho centralizado, prescritivo e vertical. Aos professores restou a opção de colocá-lo em prática. No entanto, existem algumas experiências da participação dos professores na elaboração do currículo. Este estudo analisa a participação de professores, em termos de possibilidades e limitações, na construção do currículo de ciências para as escolas públicas de Ensino Fundamental de uma das cidades mais ricas do Brasil. Trata-se de investigar o que podemos aprender com esse processo, considerando a falta de tradição nesse tipo de atuação no Brasil. Em 2013, especialistas em educação, diretores, coordenadores pedagógicos e professores participaram juntos dessa construção. A abordagem qualitativa, pesquisa-ação, orientou a coleta de dados que aconteceu por meio de entrevistas e observações realizadas com professores do Ensino Fundamental, anos finais, em um período de seis meses. Os resultados revelaram que a participação docente, com intensidades diferentes, induziu à formação e à colaboração que, no entanto, foram condicionadas por fatores intervenientes, tais como a falta de tempo, de apoio e de conhecimentos sobre o contexto. A compreensão do sentido da participação na construção do currículo fornece pistas importantes para os cursos de formação de professores, para os formadores e para os gestores escolares, que podem utilizar esses dados para preparar espaços destinados, entre outras coisas, à formação continuada.
\end{abstract}

Palavras-chave: Currículo. Ensino fundamental. Professores de Ciências.

\footnotetext{
* Doutor em Educação: Faculdade de Educação da Universidade de São Paulo. Professor dos cursos de pósgraduação em Educação e Coordenador do Observatório de Educaçao do grande ABC: Universidade Municipal de São Caetano do Sul, São Paulo, Brasil. Email: paulo.garcia@uscs.edu.br
}

$=======$

Revista e-Curriculum, São Paulo, v.15, n.o1, p. 103 - 124 jan./mar.2017

e-ISSN: 1809-3876

Programa de Pós-graduação Educação: Currículo - PUC/SP

103 


\title{
AN EVALUATION IN TEACHER PARTICIPATION IN THE CONSTRUCTION OF SCIENCE' CURRICULUM: FACTORS INVOLVED IN THE CONDITIONING OF ADVANCES
}

\author{
GARCIA, Paulo Sérgio ${ }^{\dagger}$
}

\begin{abstract}
The Brazilian tradition indicates that the curriculum elaboration, in the vast majority of the time, turned to the assistance of educational consultants in a centralized, prescriptive and vertical work. In this context, teachers have the task of putting it into practice. However, there are some experiences of teachers' participation in curriculum elaboration. This study analyzes the teachers' participation in terms of possibilities and constraints in the elaboration of the science curriculum for public elementary schools in one of the richest Brazilian cities. It means to investigate what we can learn from this process, considering the lack of tradition in this type of process in Brazil. In 2013, education experts, school principals, pedagogic coordinators and science teachers participated in this activity. The qualitative approach, action research, guided the data collection happened through interviews and observations with elementary school teachers in a period of six months. The results revealed that teacher participation, with different intensities, led to the teacher education and cooperation which, however, were conditioned by intervening factors, such as lack of time, support and understanding of the context. Understanding the sense of teacher participation in curriculum elaboration provides important clues for teacher education courses, for teacher educator, and school principals, who can use this data to prepare, among other things, continuing education.
\end{abstract}

Keywords: Curriculum. Elementary School. Science teachers.

\footnotetext{
PhD in Education: School of Education of São Paulo University. Professor of graduate courses in Education, and Coordinator of the Observatory of Education of the Great ABC: Municipal University of São Caetano do Sul. 


\section{e-Curriculum}

\section{INTRODUÇÃO}

A escola é caracterizada como uma organização social, constituída e autorizada pela sociedade para cultivar, transformar e transmitir valores sociais com o intuito de formar seus alunos. Ela é responsável, entre outras coisas, pela socialização do conhecimento e pela recriação da cultura e, nesse processo, o currículo exerce papel decisivo.

Na legislação brasileira, o currículo é concebido como o conjunto de "experiências escolares que se desdobram em torno do conhecimento, permeadas pelas relações sociais, buscando articular vivências e saberes dos alunos com os conhecimentos historicamente acumulados e contribuindo para construir as identidades dos estudantes" (BRASIL, 2010; BRASIL, 2013).

O currículo não é mais uma área somente técnica, envolvendo demandas associadas às técnicas, procedimentos e métodos. Há atualmente uma tradição crítica do currículo, orientada por questões sociológicas, políticas e epistemológicas: “Embora questões relativas ao 'como’ do currículo continuem importantes, elas só adquirem sentido dentro de uma perspectiva que as considere em sua relação com questões que perguntem pelo 'por quê' das formas de organização do conhecimento escolar" (MOREIRA; TADEU, 2013, p. 13).

Esses mesmos autores sinalizam que o currículo não é um elemento neutro de transmissão desinteressada do conhecimento social e nem atemporal. Ele pode ser considerado um instrumento social e cultural, colocado "na moldura mais ampla de suas determinações sociais, de sua história, de sua produção contextual. O currículo está implicado em relações de poder, o currículo transmite visões sociais particulares e interessadas, o currículo produz identidades individuais e sociais particulares" (MOREIRA; TADEU, 2013, p. 14).

No Brasil, em geral, a tradição indica que a construção do currículo é uma tarefa dos consultores e especialistas em educação (nacionais e internacionais), perfazendo, quase sempre, um trabalho centralizado, prescritivo e vertical. Os professores, nesse processo, ficam com a opção de colocá-lo em prática, como consumidores de rotinas prontas. Há claramente, nesse processo, a distinção clássica entre aqueles que pensam e os outros que realizam.

No entanto, nem todos compartilham da ideia de que a concepção do currículo deve ser centrada nos especialistas. Ou seja, um grupo de pessoas discute e idealiza o documento e outros ficam com a tarefa de implementá-lo. Pesquisadores (STENHOUSE, 1975; KIMPSTON; 
ROGERS, 1988; GARRETT, 1990) já enfatizam, há tempos, que os professores são as pessoas e os recursos mais indicados para o desenvolvimento e a implantação do currículo.

Nesse sentido, Saviani (2003) sinalizou que um dos maiores desafios para os professores é aquele inerente à discussão de processos de elaboração e implementação do currículo, dos quais os docentes deveriam, necessariamente, participar. A autora sinaliza que não é cabível continuar a subtrair dos professores os princípios e fundamentos de suas práticas. Nesse cenário, esses profissionais não podem ficar distantes das discussões atuais sobre os problemas dos currículos, de suas relações com questões didáticas e das matrizes teóricas das concepções de educação escolar, que embasam as propostas curriculares, as quais eles devem implementar. A autora sinaliza ainda que é preciso "[...] diminuir as desigualdades de condições nas negociações relativas às tomadas de decisão sobre o saber escolar (sua produção, sua organização em currículos e programas, as condições para sua veiculação)" (SAVIANI, 2003, p. 31).

De fato, são raras as experiências de construção do currículo em que existe a participação dos professores. Experiências como as apresentadas por Silva e Leite (2012), que mostraram resultados da participação dos professores na construção dos documentos curriculares do município de São Paulo; Noda e Galuch (2013), que revelaram a participação do professor na elaboração das diretrizes curriculares da Educação Básica do Estado do Paraná; e Schmidt e Garcia (2007), que analisaram os resultados de uma pesquisa de natureza colaborativa cujo tema e objetivo central relacionaram-se à compreensão das possibilidades e dos limites da ação docente nas decisões e inovações curriculares, são incomuns no cenário brasileiro. No entanto, sabemos que tal participação é importante para garantir que o sucesso das reformas (FULLAN; HARGREAVES, 2000), pois são esses profissionais que implementam as mudanças.

Este estudo procura fornecer mais elementos para esse debate e analisa a participação de professores, em termos de possibilidades e limitações, na construção do currículo de ciências para as escolas públicas de Ensino Fundamental da cidade com o maior Desenvolvimento Humano Municipal (IDH-M) brasileiro em 2010. Pretende-se averiguar o que podemos aprender com esse processo, considerando a falta de tradição desse tipo de atuação no país. Com esse aprendizado, entre outros objetivos, será possível elaborar teorias substantivas e indicações para futuros projetos na mesma área. 


\section{CURRÍCULO E PARTICIPAÇÃO DOS PROFESSORES}

As principais contribuições sobre a conceituação do currículo não são recentes e estão associadas ao início do século XX. Foi a publicação do livro “The curriculum”, em 1918, nos Estados Unidos, por Franklin John Bobbitt, que representou um marco no processo de teorização. Este autor considerava o currículo como um conjunto de experiências, dirigidas ou não, que objetivavam a formação das capacidades da pessoa ou, por outro lado, a série de experiências instrutivas conscientemente dirigidas que as unidades de ensino utilizavam para realizar a formação dos alunos. A definição atrela-se, então, ao conjunto ou à série de coisas que os jovens deveriam experimentar, visando ao desenvolvimento de habilidades para a vida adulta. Tal definição mostra que o currículo era endereçado à formação para a vida adulta e não se relacionava à vida infantil.

Não há um conceito único para currículo. Autores como Sacristán (1989) sinalizam que o currículo é a associação que acontece entre a cultura e a sociedade, entre a escola e a educação e entre o conhecimento e a cultura que são herdados e a aprendizagem dos alunos e, ainda, entre a teoria e a prática. Para Grundy (1987), o currículo não é um conceito, mas sim uma construção cultural. Ele não se relaciona a um conceito abstrato que esteja fora da experiência humana e é um modo de organizar um conjunto de práticas educativas.

O que se depreende desses autores, no caso de Sacristán, é que o currículo é visto como a concretização do posicionamento da escola face à cultura acumulada pela sociedade. Nesse caso, o ensino existe porque há uma cultura e o currículo é a seleção e a organização dessa cultura. Assim, o papel social da escola se realiza por meio do currículo. Em relação à definição de Grundy, o currículo é considerado como uma construção cultural que orienta as práticas educativas realizadas na escola a partir do que é produzido na sociedade, induzindo a reflexão de que ele não é neutro, ao contrário, tem uma intencionalidade muito bem definida.

Há uma estreita relação entre escola, currículo e cultura. Assim, podemos concluir que o papel social da escola realiza-se por meio do currículo. Em geral, o currículo pode ser compreendido como a conexão entre a cultura e a sociedade exterior, a escola e a educação. Trata-se da seleção de vários conhecimentos que serão transmitidos para as novas gerações. 
Como sinalizaram Moreira e Tadeu (2013):

Nesta perspectiva, o currículo é considerado um artefato social e cultural. Isso significa que ele é colocado na moldura mais ampla de suas determinações sociais, de sua história, de sua produção contextual. O currículo não é um elemento inocente e neutro de transmissão desinteressada do conhecimento social. O currículo está implicado em relações de poder, o currículo transmite visões sociais particulares e interessadas, o currículo produz identidades individuais e sociais particulares. O currículo não é um elemento transcendente e atemporal - ele tem uma história, vinculada a formas específicas e contingentes de organização da sociedade e da educação.

Anderson (2008, p. 821-823), em sua análise sobre a investigação como tema organizador do currículo de ciências (inquiry as an organizing theme for science curricula), destaca várias caracterizações para o currículo; entre elas, currículo como conteúdos, como programa ou plano de ensino, resultados da aprendizagem, reprodução cultural, experiências, conjuntos de tarefas, agenda social.

Os estudos realizados mostraram a existência de, pelo menos, três tipos de currículo, convivendo conjuntamente no cenário escolar, atuando na formação das crianças e jovens: o currículo prescrito, real e oculto. Sendo o currículo fruto de uma seleção intencional, as teorias do currículo buscam justificar porque esses conhecimentos e não outros foram selecionados. De acordo com Silva (2003, p. 15):

Nas teorias do currículo, entretanto, a pergunta "o quê?" nunca está separada de uma outra pergunta: "o que eles ou elas devem ser?", ou, melhor, "o que eles ou elas devem se tornar?". Afinal, um currículo busca precisamente modificar as pessoas que vão "seguir" aquele currículo. [...] as teorias do currículo deduzem o tipo de conhecimento considerado importante justamente a partir de descrições sobre o tipo de pessoa que elas consideram ideal. Qual é o tipo de ser humano desejável para um determinado tipo de sociedade? Será a pessoa racional e ilustrada do ideal humanista de educação? Será a pessoa otimizadora e competitiva dos atuais modelos neoliberais de educação? Será a pessoa desconfiada e crítica dos arranjos sociais existentes preconizada nas teorias educacionais críticas? A cada um desses "modelos" de ser humano corresponderá um tipo de conhecimento, um tipo de currículo.

As discussões e os debates sobre as teorias do currículo justificam as escolhas dos conhecimentos da cultura trazidos para serem trabalhados na escola. O foco de tais teorias atrelase as suas argumentações. Silva (2003) sintetiza as principais diferenças no modo de argumentação e no raciocínio das teorias: as tradicionais mostram-se neutras e científicas, desligadas e desinteressadas das relações sociais e econômicas da sociedade mais ampla. 


\section{$e$-Curriculum}

Programa de Ṕ́s-Graduação em Educação: Currículo

Reproduzem o saber dominante, os modos de pensar de acordo com as necessidades do capitalismo, concentrando-se nas questões técnicas e de organização do ensino do currículo. As teorias críticas situam-se em outra posição e não aceitam a neutralidade, pois toda teoria está implicada em relações de poder. Não se limitam à compreensão do que será ensinado, mas denunciam as razões da escolha de um conhecimento e investigam os motivos implícitos nessa escolha. Estão preocupadas com as relações existentes entre saber, identidade e poder, criticando a estrutura social existente e denunciando a premissa de que determinados conhecimentos selecionados para serem ensinados nas escolas reforçam a estrutura capitalista. Para as teorias pós-críticas, alinhadas com as teorias críticas, a formação da identidade e da subjetividade são os aspectos mais analisados no currículo.

Autores e teóricos do currículo influenciados, com diversas ênfases, pelo marxismo, investigaram a estreita relação entre a educação, a produção e a disseminação da ideologia, situando a escola como um local de reprodução da sociedade capitalista. Entre os principais representantes dessa compreensão estão Althusser (1970), Bourdieu e Passeron (1970), Baudelot e Establet (1971), Young (1971), Bowles e Gintis (1976), Pinar e Grumet (1976), Apple (1979) e Giroux (1981). No Brasil, ressaltam-se, entre outros, os trabalhos de Moreira (1992) e Moreira e Tadeu (2013).

A construção dos currículos geralmente é domínio do trabalho dos intelectuais, especialistas e consultores de educação. Ela acontece de forma externa e vertical, ou seja, é criada fora da escola, sem a participação dos professores e imposta no contexto escolar para ser cumprida pelos docentes e, tal situação, muitas vezes, obstaculiza a aceitação e a implantação do currículo, ou seja, a mudança pretendida, como já sinalizado pelas teorias da mudança educacional.

Além disso, outros fatores atuam como impeditivos das inovações e mudanças na educação, tais como a construção e implantação de um currículo novo. Fullan e Hargreaves (2000) citam a sobrecarga de trabalho; Fullan e Hargreaves (2000) e Thurler (2001) mencionam a essência individualista da profissão; Thurler (2001) discute a organização e o funcionamento da escola; Hargreaves, Earl e Ryan (2001), Thurler (2001) e Fullan (2001) debatem sobre a importância do sentido da inovação; Hargreaves, Earl e Ryan (2001) discorrem sobre o tamanho da mudança; Hargreaves, Earl e Ryan (2001), Carbonell, (2002) e Fullan (2001) discutem a questão do tempo; Fullan (2001) e Carbonell (2002) analisam a falta de apoio; Hargreaves, Earl e Ryan (2001) comentam sobre a exclusão dos alunos e pais da mudança; Thurler (2001) reflete 


\section{$e$-Curriculum}

sobre o funcionamento do diretor; Fullan e Hargreaves (2000) e Thurler (2001) debatem sobre as inovações fracassadas; Fullan e Hargreaves (2000) promovem reflexões sobre a subutilização das competências dos professores; GARCIA (2009), em um estudo sobre as inovações com professores de escola básica no Brasil, mostrou que os fatores intervenientes podem ser de ordem pessoal (falta de interesse), profissional (falta de tempo) e contextual (falta de recursos financeiros).

Desses aspectos, ressaltamos: a) a falta de sentido das mudanças para os professores, pois o sentido é um dos principais fatores que afeta os docentes e as inovações. Realizar mudanças sem a construção do sentido contribui para o fracasso das propostas de transformação (FULLAN; HARGREAVES, 2000; THURLER, 2001); b) a questão do apoio aos professores: na maioria dos projetos de inovação, os docentes não têm apoio para realizar as ações propostas. Sem apoio, as mudanças ficam comprometidas e, muitas vezes, não acontecem. Na maioria das vezes, não se possui estratégias bem definidas e sistematizadas para o apoio ao profissional; c) a questão do individualismo na profissão do professor: o individualismo e o isolamento, que de certa forma protegem o professor, também acabam limitando as trocas de experiências. Na cultura do individualismo, segundo Thurler (2001), os professores temem o julgamento do colega e da direção da escola, assim, fazem tudo para rejeitar que os erros e os fracassos fiquem visíveis aos alunos, à direção e aos pais; d) a questão do passado afetando o presente das inovações: a participação dos professores em sucessivas tentativas de reformas e inovações, que na maioria das vezes não resultaram em mudanças significativas, acabou trazendo mais sobrecarga de trabalho e ressentimentos. Esse processo afetou negativamente a motivação desses profissionais para os novos projetos que chegam à escola.

As teorias da mudança educacional já sinalizaram também que as inovações que contam com a participação dos professores têm mais chances de sucesso e de continuidade (FULLAN, 2001; CARBONELL, 2002) e é nesse contexto que os professores têm de exercer um papel central, pois as reformas, tais como a construção de um novo currículo, estão mais propensas ao fracasso quando esses profissionais são ignorados (FULLAN; HARGREAVES, 2000).

No entanto, são poucas as experiências de participação de professores na construção e implementação de currículos. Uma pesquisa sobre professores envolvidos nesse tipo de trabalho no município de São Paulo (SILVA; PONCE, 2012) revelou algumas fragilidades no processo de participação. Apesar de as autoras acreditarem que a participação estava associada à formação e à articulação dos saberes e fazeres construídos na prática pedagógica e que tal participação deve 


\section{$e$-Curriculum}

Programa de Ṕ́s-Graduação em Educação: Currículo

ser caracterizada pela força de atuação consciente, elas sinalizaram, a partir do estudo, que a participação dos educadores adquiriu um caráter residual e instrumental, contribuindo pouco com o desenvolvimento profissional e para concitar esses profissionais à responsabilidade social. As autoras afirmaram também que, para que a participação seja efetiva, determinadas condições precisam ser garantidas (tempo, lugar, divulgação, incentivo à participação), e que esses profissionais sejam conclamados a assumir a participação na perspectiva de ocupar seu espaço no trabalho, nas escolas e na sociedade.

\section{A CIDADE INVESTIGADA}

O estudo foi realizado em um município da região do Grande ABC Paulista, área metropolitana de São Paulo. A cidade confirmou sua lideranca no IDH-M, com um índice de 0,862 (em uma escala que vai de 0 a 1), tem uma das maiores rendas per capita do Brasil ( $\mathrm{R} \$$ $2.349,00)$ e sua população apresenta, em média, mais de 11 anos de estudo.

Com menor índice de mortalidade infantil no Estado de São Paulo, a cidade, em termos de dados, pode ser comparada aos países desenvolvidos (Alemanha, Áustria, Bélgica e Dinamarca). A média, no município, era de quatro óbitos de crianças menores de um ano para cada mil bebês nascidos vivos (ÍNDICE FIRJAN DE DESENVOLVIMENTO MUNICIPAL, 2009).

A cidade possuía, em 2014, 20 escolas de Ensino Fundamental com 11.249 alunos matriculados (CENSO ESCOLAR, 2013). Todas as escolas dispunham de infraestrutura avançada, de acordo com o estudo de Soares et al. (2013) - que criaram uma escala para medir a infraestrutura das escolas brasileiras.

Segundo dados do GARCIA (2014), as escolas (55\%) tinham acessibilidade para os portadores de necessidades físicas (rampa e elevadores para mobilidade de cadeirantes) e $70 \%$ apresentava salas de atendimento especial com recursos multifuncionais. Todas as salas de aula das escolas possuíam lousa eletrônica, computador e projetor tipo data show e os professores, em sua totalidade, receberam, em 2013, da Secretaria da Educação, um tablet para utilizar nas aulas.

O mesmo estudo mostrou que no Ensino Fundamental I (EFI), das 19 escolas municipalizadas, 17 delas participaram do Índice de Desenvolvimento da Educação Básica (IDEB) em 2013. Nesse segmento, a meta municipal $(6,4)$ foi alcançada por quase $80 \%$ das escolas e a meta individual atingida por, aproximadamente, $70 \%$. Todas as unidades de ensino já 


\section{$e$-Curriculum}

tinham atingido a meta de 5,7 - projetada pelo Instituto Nacional de Estudos e Pesquisas Educacionais Anísio Teixeira (INEP) para o Brasil em 2021. No Ensino Fundamental II (EFII), das 14 escolas, quase $70 \%$ participaram do IDEB e a meta municipal $(6,1)$ tinha sido atingida por $10 \%$ das unidades de ensino e $40 \%$ delas conseguiram obter ou superar a meta individual. Por fim, 90\% já atingiram a meta projetada para o Brasil $(5,1)$ em 2021.

Em relação ao IDEB, as escolas estavam evoluindo de forma diferente. O EFI apresentou evolução gradual e constante (passou de uma média de 5,9 em 2007, para 6,6 em 2013). O EFII teve queda de 2009 para 2011 e crescimento em 2013 (GARCIA et al., 2016).

\section{PROCESSO DE CONSTRUÇÃO DO CURRÍCULO}

A ideia de construir um currículo para as escolas de Ensino Fundamental, de acordo com a documentação do projeto (SEEDUC, 2013), estava associada ao fato de a cidade não possuir tal documento, único, para sua rede desde a autonomia do município (há 65 anos), à questão de que um currículo comum poderia maximizar o ensino e a aprendizagem dos alunos, à iniciativa de aproximar os professores da Secretaria de Educação e a uma estratégia deliberada de formação continuada de professores.

No planejamento do projeto estavam previstas as seguintes fases: 1) reuniões (duas) com diretores e coordenadores pedagógicos para apresentação do projeto. Nessas estavam planejadas discussões sobre as finalidades da educação de acordo com a legislação brasileira e debates sobre currículo e sua amplitude (teorias do currículo); 2) reuniões (duas) com os professores, para o mesmo trabalho da fase anterior; 3) discussão (dois meses) sobre os conteúdos escolares realizadas nas escolas nos períodos de Horário de Trabalho Pedagógico Coletivo (HTPC); 4) discussão (dois meses) sobre o currículo e os conteúdos escolares no Centro de Formação de Professores; 5) criação de grupos de estudo com diretores, professores e especialistas (três meses); 6) utilização de recursos da educação a distância para ampliar os debates; 7) realização de uma convenção do currículo, onde aconteceria a apresentação final do currículo para professores, especialistas, pais e comunidade.

Para a participação no processo de elaboração do currículo, todos os 56 professores de ciências foram comunicados por escrito e assinaram uma comunicação que continha os objetivos do projeto, as fases de elaboração e um apelo sobre a importância de sua colaboração. Aliado a esse convite, as escolas deveriam eleger, obrigatoriamente, um ou dois docentes para o trabalho. 


\section{$e$-Curriculum}

O projeto teve a duração de seis meses e as ações planejadas foram implementadas no segundo semestre de 2013. Elas contavam com um monitoramento mensal para a verificação dos avanços e a criação de eventuais ações corretivas por parte do grupo gestor. Tal grupo era formado por um coordenador geral (que era também o pesquisador) e nove formadores de professores.

\section{METODOLOGIA}

Este estudo analisa a participação de professores, em termos de possibilidades e limitações, na construção do currículo de ciências para as escolas de Ensino Fundamental de uma das cidades brasileiras mais ricas. Trata-se de investigar o que podemos aprender com esse processo, considerando a falta de tradição nesse tipo de atuação no Brasil. Os resultados possibilitarão relacionar indicações e criar teorias substantivas a partir dos dados.

Participaram do estudo todas as 14 escolas de ensino regular do Ensino Fundamental. A pesquisa-ação foi selecionada dentro do contexto da abordagem qualitativa por ser mais adequada ao tipo de estudo, considerando que o pesquisador era o coordenador do projeto, participando desde o planejamento até a análise dos resultados. Esse tipo de estudo, de acordo com Tripp (2005, p. 446-447), ocorre sistematizado em quatro etapas: planejamento da melhoria da prática; ações para implantar a melhoria; monitoramento e descrição dos efeitos da ação; e avaliação dos resultados da ação. Trata-se de um tipo de investigação que requer, entre outras coisas, participação, continuidade, problematização, intervenção e documentação do pesquisador.

Dentro da pesquisa-ação, para coletar os dados, foram utilizadas observações sistematizadas e entrevistas abertas. A observação é um procedimento em que o pesquisador pode ouvir e registrar, filmar ou gravar as informações e analisar os fenômenos in loco. Ela se relaciona a uma atividade de campo, onde o investigador estuda imerso na realidade, buscando evidências e fatos que contribuam com seu estudo. Nesta pesquisa, trata-se de uma observação sistemática, estruturada, planejada e controlada, com a utilização de protocolos e objetivos para a realização dos registros.

O processo de observação foi descritivo e reflexivo. Na parte descritiva, entre outras coisas, os registros focalizaram os sujeitos, suas falas, depoimentos e diálogos. Na parte reflexiva, as observações do pesquisador estão relacionadas às especulações, sentimentos 
experimentados no momento das observações, às ideias, às dificuldades, aos problemas encontrados, às crenças percebidas. Tudo o que poderia interferir na coleta de dados foi alvo de discussão com os membros do grupo.

O pesquisador, observador participante, se envolveu nas situações e nos eventos da construção do currículo. As relações interpessoais que aconteceram no período da pesquisa, ou seja, as conversas, diálogos, discussões, criaram envolvimentos afetivo, social e emocional. No entanto, apesar de tal envolvimento, foi criado um distanciamento cognitivo, pelo fato de o pesquisador e os professores não possuírem as mesmas preocupações.

No processo de observação, além dos registros realizados em protocolos, foi delineado um esquema para captar a intensidade da participação do professor. O pesquisador e o grupo de especialistas da Secretaria de Educação (9), que participaram de todo o projeto, criaram um indicador com as seguintes referências: fraca, para a pouca participação dos professores, quando eles opinavam pouco e as discussões quase não ocorriam; média, alguns docentes participavam das discussões, mas induzidos pelos mediadores e outras vezes algum professor monopolizava a discussão; intensa, a participação era espontânea e muitos profissionais se comunicavam, fomentando debates que induziam à formação profissional. Para a indicação de uma referência (fraca, média ou intensa) nos diversos momentos e locais onde os professores atuaram no currículo, o pesquisador se reunia com o grupo e ambos decidiam qual a referência mais apropriada para ser indicada. Nesse processo, ocorriam várias divergências entre os membros, mas no final um consenso era criado.

Em relação às entrevistas, com a participação de um total 31 professores, as informações foram coletadas sobre o perfil dos participantes: gênero, idade, formação, experiência, carga de trabalho; e sobre a participação na construção do currículo em termos de possibilidades e dificuldades. Nessa segunda questão foram investigadas, detalhadamente, a percepção dos depoentes na participação e as dificuldades enfrentadas.

Os dados foram analisados, inicialmente, pela decomposição das ideias, das opiniões, inquietações, imagens, preocupações, fenômenos e acontecimentos relatados nas entrevistas ou registrados nas anotações realizadas nas observações. A partir desse exame crítico, buscando regularidades, similaridades, diferenças e significância nos dados, surgiram os conceitos principais, sendo agrupados em categorias, com suas respectivas propriedades e dimensões.

\section{RESULTADOS E DISCUSSÃO}


Do grupo de professores que participou deste estudo, $23 \%$ dos profissionais eram do sexo masculino e 77\% do feminino; com média de idade de 35 anos; todos formados em ciências e mais de 70\%, com habilitação, algum tipo de complementação pedagógica, para atuar também no Ensino Médio.

O projeto total de construção curricular teve a duração de quase seis meses. Os momentos acontecidos nas escolas contaram com a participação de todos os 56 professores, foram organizados pelos coordenadores pedagógicos e contavam com a presença dos especialistas da Secretaria de Educação e do coordenador do projeto. Os outros espaços de participação aconteceram no Centro de Formação de Professores da cidade e incluíram 31 profissionais coordenados pelos especialistas e pelo coordenador.

A partir da análise dados provenientes das observações e das entrevistas foi possível categorizar as percepções, opiniões, ideias e depoimentos dos professores na participação da construção do currículo em três grandes categorias inter-relacionadas associadas à: 1) colaboração, 2) formação e 3) fatores intervenientes. A inter-relação resultou do efeito dos fatores intervenientes que condicionaram a colaboração e a formação.

A colaboração foi traduzida pela:

a) Participação dos professores nas reuniões iniciais no Centro de Formação para a apresentação do projeto e, ao mesmo tempo, de temas que se relacionaram com a conceitualização do currículo, com as finalidades da educação e com a legislação brasileira. Esses momentos foram considerados (pelo grupo - pesquisador e especialistas) de participação fraca, pois ocorreram poucas interferências, conflitos, perguntas e sugestões;

b) Participação nas reuniões de discussão sobre o currículo e sobre os conteúdos escolares acontecida no HTPC das escolas. Tais períodos foram considerados de intensa participação, incluindo trocas de experiência sobre quais conteúdos deveriam fazer parte do currículo, onde (trimestre) e quando (ano) deveriam ser ensinados. Nesse contexto, no entanto, aconteceram poucas discussões sobre os motivos pelos quais tais conteúdos deveriam ser ministrados (por que este conhecimento e não outro?). Nesses espaços, os docentes expunham e confrontavam suas ideias, valores, crenças, práticas de ensino com os colegas e com os especialistas, indicando momentos de reflexão e formação; 
c) Participação nos debates (dois meses) sobre o currículo e sobre os conteúdos, ocorrido no Centro de Formação. Apesar de todos os docentes terem sido convidados para essas discussões, na maioria das vezes, estiveram presentes os profissionais indicados (um) pelas escolas. Esse trabalho contou com participação intensa de seus membros, marcado pela exposição de ideias, confrontação de crenças, reflexões pedagógicas e sobre as estratégias de ensino;

d) Participação e contribuição no grupo de estudos, relacionado aos temas específicos, tais como interdisciplinaridade e temas transversais. Este foi um espaço que contou com a presença reduzida dos professores (apenas oito docentes das 14 escolas) e muitas reuniões foram canceladas. Mas quando os encontros aconteciam, geralmente, eram marcados por participação intensa de seus membros;

e) Participação com a utilização do correio eletrônico. Houve pouca interlocução desses profissionais, utilizando esta ferramenta, apesar de este ser um instrumento idealizado para sugestões e críticas. A participação, nesse caso, foi estimada como fraca;

f) Participação na convenção do currículo. Momento acontecido no auditório do Centro de Formação, contando com fraca participação dos professores. Esta foi a fase final, quando o documento foi apresentado para as autoridades, professores e pais. Ela contou com poucas intervenções, comentários ou perguntas.

O processo de colaboração ocorreu de forma diferente para cada professor. Em algumas situações ele aconteceu de forma fraca, como descrito pelo pesquisador e pelo grupo de especialistas. No entanto, ele foi mais intenso na escola com a participação de todos os professores.

A compreensão positiva do docente em relação à participação no currículo, captada sobretudo nas entrevistas, caracterizou inicialmente a categoria formação. Em geral, os profissionais sinalizaram que atuar no currículo (discutir e trocar ideias) que eles iriam implementar foi uma atividade de aprendizagem. A formação foi traduzida por momentos de troca de informações nas reuniões no Centro de Formação, nos HTPC e nos grupos de estudo. A formação também aconteceu na interlocução com especialistas e com o coordenador geral que participavam do projeto. Como descreveu um professor: "é uma oportunidade muito boa participar desta atividade. A gente troca experiência com colegas de outras escolas e pode ver o que eles estão fazendo" (PROFESSOR 05). A participação "é sempre positiva porque ninguém 


\section{$e$-Curriculum}

sabe tudo. Tenho aprendido bastante com os colegas da área e com os organizadores" (PROFESSOR 19).

A análise dos currículos (cada grupo analisou o de sua própria escola e o documento das outras 13 escolas) também se caracterizou por momentos de formação. A compreensão dos professores sobre as poucas diferenças entre os documentos em termos dos conteúdos escolares e a similaridade desses com os livros didáticos de ciências que estavam sendo utilizados no ano da investigação, possibilitaram discussões sobre o currículo, sobre os conteúdos e fomentaram a formação dos docentes.

Dados revelaram que os professores, com algumas exceções (seis docentes do total de 56), possuíam uma visão reduzida do currículo, relacionando-o com uma lista de tópicos, uma sequência de conteúdos a serem ensinados ao longo do ano e divididos em trimestres. Tais conteúdos eram aqueles que já eram ensinados e que estavam descritos, em sua grande maioria, nos livros didáticos de ciências. No mesmo sentido, a organização do currículo para esses profissionais envolvia, por um lado, a questão de pré-requisitos, como condição prévia e indispensável para a aprendizagem do aluno: "sem tais conhecimentos, condição prévia, o ensino se torna muito difícil para os jovens" (PROFESSOR 23); por outro, envolvia também a ideia de que os conhecimentos deveriam ser ensinados seguindo a premissa da complexidade: "os conteúdos têm de ser ensinados dos fáceis para os mais difíceis, todo mundo sabe disto" (PROFESSOR 14). As justificativas para essa organização sinalizavam que a aprendizagem era mais acessível, simples, compreensível e descomplicada.

A formação e colaboração, no entanto, foram afetadas por fatores intervenientes que condicionavam e limitavam os avanços. Entre os principais, estava a falta de tempo. Algumas reuniões aconteceram no Centro de Formação no período de trabalho, outras à noite ou aos sábados, dificultando a participação do professor que, muitas vezes, justificou suas ausências por compromissos com a família ou com outra escola. De fato, a literatura já sinalizou que o tempo é um fator que interfere nos projetos de mudanças (FULLAN, 2001).

Relacionada à questão do tempo está a falta de apoio. Em alguns casos, o professor não obteve autorização do diretor da escola para participar dos encontros, pois estava em horário de trabalho e atuando com os alunos. Tal situação já havia sido marcada pelas discussões de pesquisadores da área de mudança escolar, que sinalizaram que sem apoio as inovações, muitas vezes, não acontecem (FULLAN, 2001; CARBONELL, 2002). 
Outro fator importante foi caracterizado pela falta de conhecimentos, sobretudo pedagógicos, relacionados, entre outros aspectos, às teorias de aprendizagem, às teorias do currículo (críticas e pós-críticas) e à legislação brasileira. Nesse sentido, os especialistas concordavam que a participação dos professores era mais "intensa" quando as discussões eram relacionadas aos conhecimentos escolares. Os docentes se sentiam mais confortáveis nas discussões sobre o conteúdo e sobre suas experiências na sala de aula, no entanto, a participação possibilitou a compressão de alguns fundamentos da profissão e das práticas pedagógicas.

Apesar de alguns professores possuírem alguns conhecimentos sobre a interdisciplinaridade ou sobre os temas transversais, que eram ideias teóricas e metodológicas que os especialistas defendiam e mediavam para a construção do novo currículo de ciências, a ausência de formação de natureza pedagógica os induzia para uma discussão mais relacionada aos conteúdos escolares (ex: meio ambiente, corpo humano). Foi nesse sentido que os docentes defenderam a realização de um currículo sem muita inovação (ex: Ensino de Ciências por meio de atividades investigativas, interdisciplinar), ou seja, mais tradicional.

Outro fator interveniente observado relacionou-se à proteção de territórios. Em algumas situações, os espaços destinados ao debate se transformaram em momentos de defesa de ideais e ideias pessoais sobre a aprendizagem, escola e o ensino de ciências: "O ensino de ciências deve ser realizado sempre no laboratório" (PROFESSOR 09), "o aluno sempre aprende melhor quando estuda em grupo" (PROFESSOR 22). Os professores discursavam sobre o que acreditavam ser os modos mais corretos de ensinar ciência na escola. Em outros momentos, eles defendiam de forma enfática o currículo que já praticavam em suas escolas como sendo o ideal para os alunos: "a melhor sequência de conteúdos e a mais fácil e, sabe, a mais comprensível na minha opiniao para os jovens parece ser a que nós ensinamos, não é?” (PROFESSOR 5). Esses são sintomas ligados à proteção de territórios e que são próprios da compartimentalização das disciplinas (FULLAN; HARGREAVES, 2000). Em muitos casos, aproximadamente, um terço do tempo da reunião era utilizado nesse tipo de discussão e, geralmente, necessitava de uma intervenção do formador (especialista) para interromper e retomar o fluxo do trabalho. Situação que demandava um especialista com formação e experiência adequadas na condução de reuniões de professores.

Por fim, a realidade das escolas, da Secretaria de Educação e dos professores atuou como fator interveniente, condicionando o trabalho. O calendário é um desses fatores. As escolas possuíam atividades já programadas (reunião de pais, conselho de classe, período de provas) ou 


\section{$e$-Curriculum}

criavam outras ao longo do ano (multirão do lixo, gincana solidária) que afetavam a rotina estabelecida e por, consequência, as ações do projeto. Algumas reuniões foram canceladas e algumas tarefas não foram realizadas, pois as escolas jutificavam já terem atividades programadas. A Secretaria também possuía ou criava eventos, campanhas ou reuniões extraordinárias que colidiam com as datas do projeto. Nesse mesmo sentido, a própria realidade do professor, em alguns casos, funcionava como fator limitador: alguns deles ministravam aulas em várias escolas, ou seja, possuíam sobrecarga de trabalho (FULLAN; HARGREAVES, 2000). Outros não viam sentido na construção de um currículo novo (THURLER, 2001; FULLAN, 2001); outros não acreditavam mais em mudanças: um professor situou o trabalho como infrutífero, afirmando que na cidade, na educação e na escola "se discute e discute e não se muda nada... no final cada um faz do jeito que quer seu currículo e o trabalho com os alunos" (PROFESSOR 30). Tal situação ocorreu, muito provavelmente, influenciada pelo conjunto de inovações, reformas e mudanças que nunca produziram efeitos benéficos para o professor (FULLAN; HARGREAVES, 2000).

\section{CONSIDERAÇÕES FINAIS}

Compreender o sentido da participação dos professores de ciências na construção do currículo fornece pistas interessantes para os especialistas e os gestores para a idealização e implementação desse tipo de trabalho. Ao mesmo tempo, os elementos encontrados podem ser levados para os cursos de formação continuada de gestores escolares e auxiliar as secretarias de educação na implantação de projetos semelhantes.

A compreensão de tal cenário, a partir das observações e das entrevistas com professores de ciências que atuavam nos anos finais do Ensino Fundamental, deve ser entendida no contexto onde foi produzida: a cidade com o maior IDH-M do Brasil (2010), com uma rede de ensino pequena, poucos professores, com escolas próximas umas das outras e apoio das autoridades para a realização do currículo.

Neste estudo, a participação de professores na construção do currículo de ciências induziu à formação e à colaboração, sinalizando que tal processo é uma forma efetiva de levar os docentes a ampliar o entendimento sobre os princípios e fundamentos de suas práticas (SILVA; PONCE, 2012). Permitir ao professor participar do desenvolvimento do currículo, em sua área ou naquela de maior interesse, possibilita a esse profissional mostrar e desenvolver seus 
conhecimentos, habilidades e competências, realizando indicações sobre as reais necessidades dos alunos em relação às aprendizagens. Dessa forma, podemos inferir que esses profissionais devem atuar desde o desenho até a implantação e o acompanhamento do currículo. Eles se constituem em relevantes recursos nesses processos.

A participação na elaboração do currículo foi percebida de forma positiva, como um processo que favoreceu a formação em discussões em grupo, sobretudo aquelas que aconteceram nas escolas. Os professores, em geral, se mostraram colaborativos na construção do currículo, o que sugere que muitas vezes não existem momentos nem incitação, provocação e incentivos para que esses profissionais atuem em conjunto, aprendendo uns com os outros em um trabalho colaborativo. Nesse sentido, os professores não podem desistir ou mesmo renunciar à participação nas discussões do currículo escolar e devem encarar essa atuação com parte da responsabilidade social da profissão. Mesmo quando não sejam convidados para essa atividade é preciso mobilização social para a aproximação, revelando interesse em participar de algo que implicitamente é parte do trabalho pedagógico.

O esquema principal encontrado neste estudo revelou que os fatores intervenientes atuaram, condicionaram e limitaram a formação dos professores e a colaboração entre eles. Tais fatores estão atrelados aos contextos das escolas e da Secretaria de Educação. Acrescidos a esses condicionantes estão outros, associados à falta de conhecimento, de tempo e de apoio ao professor, ou seja, sua realidade.

O processo de colaboração por meio da participação não foi o mesmo para cada professor. Os momentos mais intensos, na opinião dos especialistas, com a participação da maioria dos professores, aconteceram nas escolas, indicando que tal espaço permite ao professor maior tranquilidade, mais liberdade para exprimir sua opinião e menos pressão para participar e aprender. Além disso, o HTPC sofre menos interferências externas: as datas são fixas, ele acontece na própria unidade de ensino, não há deslocamento do docente e trata-se de um local com o qual o profissional já está mais familiarizado. Mesmo nesses espaços, no entanto, ocorreram algumas interferências: algumas vezes eles eram cancelados (atendimento de pais urgente), em outras o tempo era quase todo utilizado para o cumprimento de recados administrativos, noutras ainda eram usados para reuniões de pais.

Uma das lições trazidas pela análise e discussão dos dados deste estudo relaciona-se à questão da importância do conhecimento e da intervenção para a redução/eliminação dos fatores intervenientes que condicionam e restringem os avanços na formação do professor. As 


\section{$e$-Curriculum}

indicações mostraram que é preciso conhecer e considerar, detalhadamente, o contexto das escolas, das secretarias de educação e da realidade dos professores para que a participação docente na construção do currículo seja mais proveitosa. 


\section{REFERÊNCIAS}

ALTHUSSER, L. Ideologia e Aparelhos ideológicos de estado. Lisboa: Presença 1970.

ANDERSON, R. D. Inquiry as an organizing theme for science curricula. In: S. K. Abell; N. G. Lederman (Eds.). Handbook of research on science education. 2007, p. 807-830.

APPLE, M. Curriculum and ideology. London: Routledge \& Kegan Paul.

BAUDELOT, C.; ESTABLET, R. L’École capitaliste en France. Paris: Librairie Françoies Maspero, 1971.

BOURDIEU, P.; PASSERON, J. C. La Reproduction; éléments pour une théorie du système d'enseignement. Paris: Minuit, 1970.

BOWLES, S.; GINTIS, H. Schooling in Capitalist America. New York, Basic Books. SILVA, Tomaz Tadeu. Documentos de Identidade: uma introdução às teorias do currículo. Belo Horizonte: Autêntica, 2004.

BRASIL, Ministério da Educação . Diretrizes Curriculares Nacionais Gerais para a Educação Básica, 562p, 2013.

. Resolução CNE/CEB no 4/2010. Define Diretrizes Curriculares Nacionais Gerais para a Educação Básica. Diário Oficial da União, [da República Federativa do Brasil], Brasília. DF, 14 jul. 2010. Seção I, p. 824.

CARBONELL, J. A aventura de inovar: a mudança na escola. Porto Alegre: Artmed, 2002.

SECRETARIA DE EDUCAÇÃO DE SÃO CAETANO D SUL. (SEEDUC). Documentação básica do currículo de Ciências para o Ensino Fundamental. Documento da Secretaria de Educação, 2013.

FULLAN, M. The New Meaning of Educational Change. 3a Ed., N.Y: Teaches' College Press, 2001.

FULLAN, M.; HARGREAVES, A. A escola como organização aprendente: buscando uma qualidade para a Educação. Porto Alegre: Artmed, 2000.

GARCIA, P. S.. Inovações e Mudanças: por que elas não acontecem nas escolas ? Uma macroanálise envolvendo professores de ciências. 1. ed. São Paulo: LCTE Editora, 2010.

. Um estudo de caso analisando a infraestrutura das escolas de ensino fundamental. Cadernos de Pesquisa: Pensamento Educacional (Curitiba. Online), v. 9, p. 153-175, 2014. 


\section{e-Curriculum}

Programa de Ṕ́s-Graduação em Educação: Currículo

GARCIA, P. S.; PREARO, L. C.; ROMERO, M. C.; SECCO, A.; BASSI, M. S. School performance: An IDEB analysis of the seven municipalities in the ABC region. Revista Eletrônica de Educação (São Carlos), v. 10, p. 115-134, 2016.

GARRETT, R. M. The Introduction of School-based Curriculum Development in a Centralised Education System: A Possible System. International Journal of Educational Development. $\mathrm{n}$. 10, p. 303-309, 1990.

GIROUX, H. Ideology, Culture and the Process of Schooling. London, The Falmer Press, 1981.

GRUNDY, S. Curriculum. The Falmer Press, 1987.

HARGREAVES, A.; EARL, L.; RYAN, J. Educação para a Mudança. Recriando a escola para os adolescentes. Porto Alegre: Artmed, 2001.

ÍNDICE FIRJAN DE DESENVOLVIMENTO MUNICIPAL (2009). Disponível em:

<http://www.firjan.org.br/ifdm/>. Acesso em 23 de abril 2013.

KIMPSTON, R. D.; ROGERS, K. B. Predispositions, participatory roles and perceptions of teachers, principals and community members in a collaborative curriculum planning process. Journal of Curriculum Studies, v. 20, n. 4, p. 351 -367, 1988.

MOREIRA, A. F. B. O campo do currículo no Brasil: construção no contexto da ANPEd.

Cadernos de Pesquisa, n. 117, p. 81-101, 2002.

MOREIRA, A. F. B. e SILVA, T. T. (Orgs.). Currículo, cultura e sociedade. S.P.: Cortez, 13 ED. 2013.

NODA, M.; GALUCH, M. T. B. O Trabalho do professor na elaboração de currículos escolares: diretrizes curriculares da educação básica do estado do Paraná. Anais Seminário de Pesquisa do PPE. Universidade Estadual de Maringá, 2013.

OBSERVATÓRIO DA EDUCAÇÃO DO GRANDE ABC. Relatório do primeiro trimestre. Universidade Municipal de São Caetano do Sul. 2015.

PINAR, W. F., GRUMET, M. R. Toward a Poor curriculum. Dubuque, Kendall Hunt Publishers, 1976.

SACRISTÁN, G. J. El Currículum una reflexión sobre la práctica. Madrid: Morata, 1989.

SAVIANI, N. Currículo um grande desafio para o professor. Revista de Educação, n. 16, p. 35$58,2003$.

SCHMIDT, M. A. M. S.; GARCIA, T. M. F. B. Professores e produção do currículo: uma experiência na disciplina de História. Currículo sem Fronteiras, v. 7, n.1, p. 160-170, 2007. 


\section{$e$-Curriculum}

Programa de Pós-Graduação em Educação: Currículo

SILVA, T. T. da. Documentos de identidade: uma introdução às teorias do currículo. $2^{\mathrm{a}}$ ed. Belo Horizonte: Autêntica, 2003.

SILVA, F. R.; PONCE, B. J. A participação dos professores na construção dos documentos curriculares do município de São Paulo: uma questão inerente à prática docente. XVI ENDIPE Encontro Nacional de Didática e Práticas de Ensino: Unicamp, 2012.

SOARES NETO, J. J. et al. Uma escala para medir a infraestrutura escolar. Estudos em Avaliação Educacional, São Paulo, v.24, n.54, p.78-99, 2013.

STENHOUSE, L. An Introduction to Curriculum Research and Development. London: Heinemann. 1975.

THURLER, M. G. Inovar no interior da escola. Porto Alegre: Artmed, 2001.

TRIPP, D. Pesquisa-ação: uma introdução metodológica. Revista Educação e Pesquisa, São Paulo, v. 31, n. 3, p. 443-466, 2005.

YOUNG, M. Knowledge and Control: New Directions for the Sociology of Education. London, Collier Macmillan, 1971.

Artigo recebido em 17/03/2016.

Aceito para publicação em 09/11/2016. 